\title{
CONTEMPORARY PSYCHOTHERAPY RESEARCH, PSYCHODYNAMIC PSYCHOTHERAPY AND JUNGIAN ANALYSIS
}

\author{
Christian ROESLER ${ }^{1), 2), 3)}$ \\ ${ }^{1)}$ Catholic University of Applied Sciences Freiburg, Germany \\ ${ }^{2)}$ University of Basel, Switzerland \\ ${ }^{3)}$ Kyoto University, Japan
}

\begin{abstract}
Even though Jungian Analytical Psychotherapy has a tradition of more than 100 years, little is known about the empirical status of the therapy method. This article gives an overview of the evidence found for Psychodynamic Therapy in general and for Jungian Psychotherapy, on the background of the state of the art in psychotherapy research. Though there is great diversity in study designs, some of which are hampered by strong limitations to internal validity, all of the studies reported here found significant improvements in the dimensions investigated, with effect sizes ranging from moderate to very large. There are even indicators of cost effectiveness of Jungian psychotherapy. The results point towards the effectiveness of Jungian psychotherapy, but there is still a strong need for further research, namely Randomized Controlled Trials (RCTs), to make firm conclusions on efficacy of the method possible. Since Jungian Psychotherapy is an established method in the health care systems of Germany, Switzerland, Austria, Japan and other countries these results confirm the practicability and contribution to the treatment of mental health problems of this method.
\end{abstract}

Key words: Jungian Analytical Psychotherapy, Psychodynamic Psychotherapy, psychotherapy research, effectiveness, cost-effectiveness

\section{INTRODUCTION}

Carl Gustav Jung (1875-1961) is one of the founding fathers of modern psychotherapy. After some years of collaboration with Freud at the beginning of the 20th century, Jung broke ties with Freud in 1912 and developed his own psychoanalytic approach, later called Analytical Psychology (AP). Jung had a major influence on the development of psychotherapy. His use of creative techniques made him the founder of art therapy methods; he was the first to use techniques of imagination to influence the inner world of patients, a method that has recently been adopted in a number of psychotherapy approaches (e.g., the treatment of posttraumatic stress disorder); and he was the first to postulate that in the training of psychoanalysts there should be an extensive training analysis. In spite of this influence and the fact that Jungian psychotherapy is well established all over the world in mental health care as well as in training structures, there are few publications on the empirical foundations of Jungian

Correspondence concerning this article should be addressed to Christian Roesler, Catholic University of Applied Sciences Freiburg, Germany (e-mail: christian.roesler@kh-freiburg.de). 
psychology and the effectiveness of Jungian psychotherapy.

Although Jungian psychotherapy has a long history and has been practiced for more than 100 years, the Jungian approach has long been criticized for a lack of proof of its effectiveness. At the beginning of the 1990s some psychotherapy researchers (e.g., Grawe et al., 1994) therefore claimed that Jungian psychotherapy should be banned. This initiated the first attempts by a number of Jungian training institutes to conduct empirical studies on the effectiveness of Jungian psychotherapy. The majority of these studies were conducted in the German speaking countries, since here the conditions for doing effective research were comparably good. In Switzerland, because of its long tradition, Jungian psychotherapy is one of the largest schools of psychotherapy with considerable resources that enabled systematic research. In Germany Jungian psychotherapy has been financed by public health insurance since 1967, along with Freudian and Adlerian therapies. It is thus well established in the healthcare system with a strong professional society (Deutsche Gesellschaft für Analytische Psychologie [German Association for Analytical Psychology; DGAP]) and three major training institutes. In the German healthcare system patient data have to be stored by the public insurer (the Krankenkasse in German) for decades and several of the studies reported below made use of these records for investigating long-term effects of Jungian psychotherapy.

The aim of this article is to give an overview of the evidence for Jungian psychotherapy on the background of contemporary psychotherapy research and the evidence found for psychoanalytic therapies in general.

\section{Jungian Method of Analytical Psychotherapy}

There are some characteristic differences between AP and classical Freudian psychoanalysis in theory as well as in the practice of psychotherapy. In Jung's view, the unconscious is not just a container for repressed drives and conflicts but it also contains constructive forces. At the center of the psyche a structure called the Self moves the personality towards its potential wholeness. This is seen as a spontaneous process called Individuation. From this perspective, the unconscious consists not only of a personal sphere but also of a collective part that contains the archetypes, universal psychological structures that influence the formation of the personality. Archetypal elements come into mind by way of symbols, which contain condensed information about the direction the ego has to take towards greater wholeness. Since the archetypal symbols contain universal information they can be interpreted by referring to cultural knowledge from mythology, religious and spiritual traditions, anthropology, etc. Psychological disorders are explained as being an expression of a strong tension between the direction of ego consciousness and the unconscious with its tendency to strive towards greater wholeness of the personality. If the ego becomes one-sided and splits off other parts of the psyche so that they become incompatible with conscious functioning, the tension thus created can lead to neurotic suffering and symptoms. In Jungian psychology the unconscious is thus seen as a helpful force that tries to support ego consciousness in integrating split-off 
parts of the psyche. The unconscious in this process produces symbols and presents them to ego consciousness by way of dreams, fantasies, spontaneous creative acts, and also symptoms. This is the reason why Jungian psychotherapy makes use of dream interpretation as well as of different kinds of creative methods to give the unconscious the possibility to express itself. Jungian psychotherapy also focuses on the transferencecountertransference relationship in very much the same way as the Freudian tradition does.

\section{PSYCHOTHERAPY RESEARCH}

\section{Levels of Evidence}

In empirical research there is a differentiation between different levels of studies (Wampold \& Imel, 2015). The highest level or Gold Standard is the Randomized Controlled Trial (RCT), with an experimental and a control group and participants who are randomly divided into these groups. Only RCTs can give proof of the efficacy of a psychotherapy method which means that the effects in the patients are a result of the method alone, and not of other extratherapeutical factors (i.e., internal validity). In general only RCTs are accepted as a proof for the efficacy of the psychotherapy method. In recent years though there has been a discussion about the validity of RCTs, since their internal validity is high, but the external validity, its applicability to every day practice, is low (Westen \& Morrison, 2001). Several researchers have argued for naturalistic studies, which are conducted in every day practice and therefore are much better applicable to real practice conditions. In Germany the legal body responsible for accreditation of psychotherapy methods (Wissenschaftlicher Beirat Psychotherapie [WBP]) meanwhile has defined new regulations asking for a combination of RCTs and naturalistic studies for psychotherapy methods to become accredited in the German healthcare system. Here empirical studies giving proof for the efficacy and effectiveness of psychotherapy methods need to be not only high in internal validity but also in external validity to be applicable for everyday practice (Nübling et al., 2014). Generally speaking prospective data are more valid than retrospective, since retrospective studies are subject to biases, e.g., only those patients participate who benefited from the therapy.

\section{Evidence Base of Psychoanalytic and Psychodynamic Psychotherapies}

Not well known even to many psychoanalytic practitioners, there is a long history of effectiveness research in psychoanalysis (Luborsky et al., 1975). There is solid evidence for psychodynamic psychotherapies, with some less solid results for long-term intensive psychoanalytic treatment (see Yakeley, 2018, for a recent overview). The term psychodynamic psychotherapy is usually considered to be a broader umbrella concept for different psychotherapy modalities applying psychoanalytic principles.

Since the 1990s there has been an increasing number of empirical studies, RCTs, 
meta-analyses and systematic reviews, which give proof of the efficacy of short-term and long-term psychodynamic psychotherapy for a broad range of mental disorders; the effect sizes found for improvement are as large as for other evidence-based therapies, e.g., cognitive behavioral therapy (CBT), so that it is no longer possible to speak of a superiority of CBT over psychoanalysis (Leichsenring \& Klein, 2014; Leichsenring et al., 2015). The disorders treated effectively with psychodynamic psychotherapy include depressive and anxiety disorders, somatoform disorders, eating disorders, complicated grief, personality disorders, substance related disorders, and posttraumatic stress disorder. "Most of these studies investigated short-term psychodynamic psychotherapies ( 8 to 40 sessions). However, some evidence suggests that long-term psychodynamic psychotherapy (12-36 months) in complex mental disorders is effective. In several meta-analyses, longterm psychodynamic psychotherapy was significantly more effective at improving target problems, general psychiatric symptoms, and personality and social functioning than were shorter or less intensive forms of treatment in patients with complex mental disorders, defined as chronic mental disorders, personality disorders, or multiple comorbid disorders. These findings are consistent with data on dose-effect relations, which suggest that for many patients with complex mental disorders, including chronic mental disorders and personality disorders, short-term psychotherapy is not sufficient. Moreover, some evidence indicates that long-term treatments have better longer-term outcomes following cessation of therapy than do short-term treatments, and that effect sizes might not become evident until some time after treatment has ceased, suggesting the need for longer-term follow up" (Yakeley, 2018, p. 5).

An example for the findings regarding the differences between long-term and shortterm psychotherapies is the Munich depression RCT study (Huber et al., 2012), which compared long-term psychoanalytic psychotherapy with short-term psychodynamic psychotherapy and behavioral therapy in the treatment of chronically depressed patients. There were no differences between the treatment conditions at the end of therapy, but one year post therapy the psychoanalytic treatment resulted in significantly higher effect sizes for a number of measures. These differences between the treatment conditions increased in a three-year follow-up, so that in the CBT condition up to $60 \%$ of the patients, even those who had initially positive results, experienced a relapse to a clinically significant condition of depression, whereas the number of patients in the psychoanalytic treatment who did not fulfill the criteria for a clinically significant depression even increased from end of therapy to the three-year follow-up.

Apart from these findings on outcome, process research has provided evidence for a connection between positive treatment results and specific psychoanalytic treatment methods, e.g., focus on emotions: Therapist facilitation of patient affective experience/ expression was positively associated with treatment improvements, and this relationship most likely exists independently of the influence of other factors; the results suggest a $30 \%$ difference in success rate between patients who received an affective therapeutic focus and those who do not. It was also found that if transference interpretations focus on the central unconscious need of the patient this is positively related with the development of the therapeutic relationship and the outcome. 
Even though there has been considerable research on psychodynamic therapies, there is still a number of problems connected with investigating psychoanalytic treatments: "These challenges include the following: the poor methodology of many existing studies, such as unclearly defined patient samples or treatment methods, absence of adequate controls, and insufficient monitoring of adherence to the treatment model and inter-rater reliability; resistance within the psychoanalytic community to research methods such as the manualisation of treatments, randomisation of patients, recording of therapy sessions, studying of narrowly defined research samples that are not representative of clinical practice, and scepticism within the community as to whether unconscious conflicts, defences, and fantasies can be measured; and, finally, difficulties in investigating longer-term treatments and outcomes" (Yakeley, 2018, p. 4).

\section{Common Factor Models in Psychotherapy Research}

For some years now there has been a trend towards looking at common factors in different schools and models of psychotherapy, instead of comparing the results of different schools in the sense of a competition. There is also a shift away from manualized treatments focusing on specific disorders towards transdiagnostic treatment methods, which focus on similarities among disorders, particularly those in similar classes of diagnoses that are associated with a high risk of comorbidity. "This approach could be particularly suited to psychodynamic psychotherapy, because it is traditionally less tailored to the symptoms of single mental disorders, rather than problems, especially in the relational sphere, that are common to many mental conditions, and promotes a dimensional model of classification focusing on the core underlying processes of mental conditions" (Yakeley, 2018, p. 5). The most prominent of these models and also the latest, developed from the insights found in psychotherapy research across all kinds of schools and approaches, is the Contextual Metamodel (Wampold \& Imel, 2015). The main elements of this model are: Therapeutic alliance, i.e., the capacity for empathy in the therapist is the best predictor for outcome; Creation of hope in the patient is decisive, dependent on the acceptance of the theoretical model; Allegiance, i.e., the belief of the therapist in the effectiveness of the method is a strong predictor for outcome; large differences were found between individual therapists, so the personality of the therapist seems to play a major role; all of these elements create a holistic experience of healing, so that the average effect size of this kind of psychotherapy is .75-.85, which is equivalent with an $80 \%$ probability that the patient will be better off after therapy. This model has strong parallels with imperatives for therapy formulated already by Jung, who pointed to the importance of a training analysis for developing the personality of the therapist; he also emphasized the personal therapeutic relationship over the method; and he emphasized the unconscious interaction between the two persons, which today is discussed as placebo effect or creation of positive expectancy. 


\section{Research on Jungian Psychotherapy}

Even though Jung started his career as a researcher at the psychiatric hospital of the University of Zürich and received international reputation around 1905 because of his empirical research with the Association Experiment, after 1912 and his break with Freud Jung never took up empirical research again. This might be the reason why in the Jungian community a more skeptical attitude towards empirical research developed over the years. Only recently have there been systematic attempts to investigate Jungian concepts empirically. Reviews of the literature show that many of Jung's concepts are empirically supported today (Roesler, 2018). There is a certain controversy about Jung's central concept of the archetype (Roesler, 2012), but other concepts have found their way into academic psychology, such as the personality dimension introversion-extraversion, which has become one of the so-called big five in personality psychology and is part of most well-established personality inventories.

In the field of psychotherapy research the skepticism about empirical methods in the community of Jungian practitioners has created some obstacles to the conduct of

Table 1. Overview of Studies Investigating Jungian Psychotherapy

\begin{tabular}{|c|c|c|c|c|}
\hline Authors & Study & Design & $N$ & Results \\
\hline $\begin{array}{l}\text { Mattanza et al. } \\
(2006)\end{array}$ & $\begin{array}{l}\text { Praxisstudie Analytische } \\
\text { Langzeittherapie (PAL) } \\
\text { Schweiz (Outpatient } \\
\text { analytical long-term } \\
\text { psychotherapy Switzerland) }\end{array}$ & $\begin{array}{l}\text { Prospective naturalistic } \\
\text { outcome study w/ follow- } \\
\text { up, one group design }\end{array}$ & 37 & $d=0.71-1.48$ \\
\hline $\begin{array}{l}\text { Rubin and } \\
\text { Powers (2005) }\end{array}$ & $\begin{array}{l}\text { San Francisco Psychotherapy } \\
\text { Research Project }\end{array}$ & $\begin{array}{l}\text { Prospective naturalistic } \\
\text { outcome study w/ follow- } \\
\text { up, one group design }\end{array}$ & $\begin{array}{c}39 \\
(57)\end{array}$ & $\begin{array}{l}\text { Significant } \\
\text { reductions in } \\
\text { Symptom Check } \\
\text { List-90 } \\
\text { Item-Revised } \\
\text { Version (SCL-90- } \\
\text { R), Inventory of } \\
\text { Interpersonal } \\
\text { Problems (IIP) }\end{array}$ \\
\hline $\begin{array}{l}\text { Tschuschke et } \\
\text { al. (2015) }\end{array}$ & $\begin{array}{l}\text { Praxisstudie ambulante } \\
\text { Psychotherapie Schweiz } \\
\text { (PAP-S; Naturalistic } \\
\text { psychotherapy study on } \\
\text { outclient treatment in } \\
\text { Switzerland) }\end{array}$ & $\begin{array}{l}\text { Prospective naturalistic } \\
\text { outcome study, } \\
\text { multigroup design }\end{array}$ & 81 & $\begin{array}{l}\text { Effectiveness given } \\
\text { for all schools } \\
\text { investigated }\end{array}$ \\
\hline $\begin{array}{l}\text { Keller et al. } \\
(2002)\end{array}$ & Berlin Jungian Study & $\begin{array}{l}\text { Catamnestic/retrospective } \\
\text { study }\end{array}$ & 111 & $\begin{array}{l}\text { Reduction of } \\
\text { symptoms to "normal } \\
\text { health state" for } 88 \%\end{array}$ \\
\hline $\begin{array}{l}\text { Breyer et al. } \\
(1997)\end{array}$ & $\begin{array}{l}\text { Konstanz Studie - A German } \\
\text { consumer reports study }\end{array}$ & $\begin{array}{l}\text { Catamnestic/retrospective } \\
\text { study }\end{array}$ & 646 & $\begin{array}{l}\text { Significant benefits } \\
\text { in health and well- } \\
\text { being }\end{array}$ \\
\hline
\end{tabular}


effectiveness studies (see below). Practitioners worry that research might interfere with the therapeutic relationship and they have raised questions about how to catch the details of the psychotherapeutic process methodically. The studies reported below (see Table 1) have found solutions to these questions: Different measures have been designed to tap into different aspects of the psychotherapeutic process characteristic of analytical psychotherapy. Operationalized Psychodynamic Diagnostics (OPD) have been developed to systemize diagnostic steps in psychoanalysis and this procedure has been adapted to Jungian psychotherapy (Junghan, 2002). The "Heidelberger Umstrukturierungsskala" (Heidelberg scale for changes in personality structure) and measures for analytic foci, therapeutic alliance and transference are just a few examples of tools that were developed to systematically investigate different aspects of the psychotherapeutic process.

\section{Praxisstudie Analytische Langzeittherapie (PAL) Schweiz (Outpatient Analytical Long-} Term Psychotherapy Switzerland; Mattanza et al., 2006)

A group of researchers at the Jung Institute in Zürich participated in a larger German study of long-term analytical psychotherapy (Rudolf et al., 2004) conducted at the University of Heidelberg. This was a naturalistic prospective outcome study; patients were monitored from the beginning of therapy in the usual everyday practice context (no control group). 26 therapists with 37 cases participated. $57 \%$ of these patients suffered from depressive disorders and $47 \%$ of them had personality disorders. The burden of disease in the sample was therefore considerably high. The mean duration of treatment was 35 months (ranging from 8.5 to 60 months) with a mean of 90 sessions (minimum: 21, maximum: 190), which is equivalent to a low-frequency treatment. The sample was compared with a representative sample from a study conducted in Zürich investigating outpatients of psychiatric practices (Bischof et al., 1994) and was considered representative for Jungian psychotherapy in Switzerland. Measures were applied before the beginning of therapy, after three and six months and then every half-year during the course of therapy, after completion of therapy and in a one- and three-year follow-up.

Measures (for more details see Mattanza et al., 2006): Researchers: external experts conducted interviews with patients at all points of measurement and these were videotaped and rated using OPD (Junghan, 2002); based on these ratings for every patient individual Psychodynamic Foci were defined and the development of these foci was tracked over the course of psychotherapy. Changes in personality structure were measured over the course of therapy using the Heidelberger Umstrukturierungsskala (Rudolf et al., 2004). Videotaped interviews with experts were also used to investigate changes in life conduct. Patient functioning was assessed using the Social and Occupational Functioning Assessment Scale (SOFAS) and the Global Assessment of Functioning Scale (GAF). Experts also rated therapeutic alliance and transference on specialized rating manuals (Scale for Global Rating of Transference [SGRT], Tabelle zur Einschätzung der analytischen Beziehung [Tables for rating of analytical relationship; TAB]). Interrater reliability for all the above-mentioned measures was above $r=.75$ over all points of measurement. The participating therapists rated the severity of physical and psychological symptoms by applying ICD-diagnosis and Beeinträchtigungsschwerescore (BSS, severity 
of symptoms score) and applied status and process ratings. Patients filled out questionnnaires (Symptom Check List-90 Item—Revised Version [SCL-90-R], Psychischer und sozialkommunikativer Befund-Selbsteinschätzung [psychological and social communicative Diagnosis — self evaluation; PSKB-Se-R]), Inventory of Interpersonal Problems [IIP], a personality inventory (Trierer Persönlichkeitsfragebogen [TPF]), and gave admission to use their health insurance data. General functioning of patients was moderately reduced at the beginning of therapy (mean of 74), interpersonal problems were comparably severe (mean: 1.8), psychological symptoms were severe in $80 \%$ of patients, as were social and communicative deficits in $90 \%$ of patients. Mean duration of symptoms was 6.7 years.

Results: Positive restructuring of patients' personality towards more consciousness, better coping, and solution of major problems (effect size: $d=0.94$ ). This resulted in positive changes in everyday life conduct with a very high effect size $(d=1.48)$. Physical symptoms were reduced with an effect size of $d=1.08$ and psychosocial symptoms with $d=1.43$. Global Severity Index of the SCL-90-R was reduced from 0.71 to 0.28 which is equivalent to a normal level at the end of therapy, whereas reduction had a very high effect size $d=1.31$. The symptom scales of PSKB for anxiety, physical symptoms, depression, and suicidality were combined and their mean values reduced from 57.21 to 48.69 with an effect size of $d=1.01$. Interpersonal problems (IIP) were reduced with a medium effect size of $d=0.71$. All the reductions mentioned were highly significant. All results remained stable after 1 year and 3 years. There are findings for further positive changes between the end of therapy and follow-up.

\section{San Francisco Psychotherapy Research Project (Rubin \& Powers, 2005)}

Originally this naturalistic study conducted by the San Francisco Jung Institute was designed as a prospective outcome study with four points of measurement (pre and post therapy, one-year, and five-year follow-up). Measures: SCL-90-R; IIP, GAF. The participants were patients of the outpatient clinic of the San Francisco Jung Institute; of 100 patients 57 participated in the study. Because of low participation of analysts from the Institute the project had to be terminated earlier and the original design had to be collapsed into a one-group pretest-posttest-design. This included 39 of the original 57 patients and only part of these completed follow-up. So the internal validity of the study could not be secured. There were significant reductions in SCL-90-R and IIP.

\section{Berlin Catamnestic Study (Keller et al., 2002)}

In the early 1990s the Empirical Psychotherapy Research Group in Analytical Psychology of Berlin conducted a nationwide catamnestic, retrospective study. Former patients of Jungian psychotherapies were asked to participate and were tested via questionnaires and interview. In Germany psychotherapy is financed quite generously by the health care system (up to 300 hours of analysis); at the beginning of therapy the therapist has to apply for financing. These applications contain data about the health state and symptoms of the patient, personality, social context, psychodynamics, and diagnosis. This information is stored by the ministry of health for decades; the Berlin 
study made use of these and other health care utilization data. Diagnoses: $46 \%$ affective disorders, $24 \%$ other neurotic and psychosomatic disorders, $17 \%$ personality disorders. The mean duration of treatment was 162 sessions with a frequency of 1 to 2 sessions per week. Measures included life satisfaction, well-being, social functioning, personality traits, interpersonal problems, health care utilization, and standardized measures (SCL90-R, Veränderungs-Evaluation [Evaluation of therapeutic change; VEV], Gießen-Test). The severity of symptoms before treatment was assessed using the Schepank method of impairment severity index (Schepank, 1994).

Results: Of $60.4 \%$ of patients reporting their well-being as very poor (severe set of diagnoses) prior to therapy, $86.6 \%$ rated their global well-being at follow-up as very good, good or moderate (well-adjusted close to normal reference group on all scales of psychopathology). Six years after the termination of treatment $70-94 \%$ reported good to very good improvements in psychological distress, general well-being, life satisfaction, job performance, partner and family relations, and social functioning. The global health state of $88 \%$ could be described as "normal health" compared to a calibration sample (Gerdes \& Jäckel, 1992). The findings in SCL-90-R and Gießen-Test showed no difference to the standardization samples, the subjects fell within the normal range on all scales.

There were also significant reductions in health care utilization. The mean number of 16 days lost due to sickness in the 5 years before psychotherapy was reduced to a mean of 8 days in the 5 years after the end of therapy. The mean number of 8 days of hospitalization in the year before psychotherapy was reduced to a mean of 1 day after the end of therapy. There was also a reduction of visits to primary care services below the level of two representative studies of private practice patients (Hoffmeister et al., 1988; Schach et al., 1989) and a reduction in intake of psychotropic drugs. All of these reductions were statistically significant. In sum, Jungian psychotherapy appeared to reduce the health insurance claims of the patients even below the level of the average German member of the health insurance system. In sum, there was not only a high level of satisfaction on the part of the patients with the Jungian treatment but there was also a reduction in symptoms which moved the patients into the area of normal health. The effects of psychotherapy were long-lasting and touched all areas of the life of the patients so that even the use of healthcare services was so drastically reduced that Jungian therapy was also cost-effective in the long run. These results have to be interpreted on the background of limitations of the design even though the study made great efforts to control for biases.

\section{Konstanz-Studie (Breyer et al., 1997)}

The study conducted in Konstanz/Germany is a replication of the famous Consumer Reports Study by Seligman applied to therapies from several psychodynamic schools (20\% Jungian) and in its design comparable to the above-mentioned Berlin study. The results are very much comparable to those of the above-mentioned Berlin study, in all dimensions the study found significant benefits in health and well-being. There were again significant changes between end of therapy and follow-up. As in the Berlin study 
health insurance data were used and it was found a highly significant reduction in health utilisation parameters. All of these results remained stable in a six-year follow-up. A special aspect of this study is a cost-benefit computation: there were significant savings accrued as a result of individual and group psychotherapy in the first two years after therapy. These were significantly higher in relation to the severity of the health status of the patient at the beginning of therapy.

\section{Praxisstudie Ambulante Psychotherapie Schweiz (PAP-S; Tschuschke et al., 2015)}

The Naturalistic Psychotherapy Study on Outpatient Treatment in Switzerland, conducted by the Swiss Charta for Psychotherapy, had the main goal of comparing different types of psychotherapy with regard to specific and nonspecific common therapeutic factors. The design is comparable to that of the Zürich Jungian study but investigated eight different schools of psychotherapy, mainly from the psychodynamic and the experiential field. The choice of measures applied followed the recommendations given by the Society for Psychotherapy Research and includes outcome as well as process variables. The study ran for 7 years (2006-2012), including therapies and follow-up. The overall sample includes 379 clients. In the general results of the study all the participating schools of psychotherapy were found to be effective with effect sizes ranging from 0.61 to 1.12 (Tschuschke et al., 2015). One part of the study consisted of describing the interventions applied by the different schools in detail. In the study, therapies were videotaped and external raters evaluated which of the described interventions were practically applied. In each school the majority of interventions applied was not school-specific but either general or stemming from a different school. Only about $15 \%$ of the interventions came from the specific background of the therapist. This of course automatically raises the question of whether there even is a specificity in the practical therapeutic work of Jungian therapists and what that would be.

\section{Discussion}

As there are no RCTs and the internal validity of the above-mentioned studies can be questioned, at the moment there is no conclusion possible regarding the efficacy of Jungian psychotherapy. On the other hand the reported studies due to their naturalistic designs have to be considered high in external validity. All of the studies found improvements on all of the dimensions investigated, with moderate to large effect sizes on symptom reduction, well being, interpersonal problems, change of personality structure, reduction of health care utilisation, changes in everyday life conduct. All of these effects are stable in follow-up up to seven years after therapy. There are even further positive changes between termination and follow-up. The majority of patients seem to have benefited from Jungian psychotherapy, health care utilization parameters were significantly reduced so that there are also indicators for cost effectiveness. These results are comparable to the effects found for psychodynamic therapies in general. At this point it could be questioned whether Jungian psychotherapy should still be regarded 
as different or special in regards to others psychoanalytic approaches. If Jungian psychotherapy would regard itself as just one of a field of different psychodynamic approaches there would be no need to provide empirical evidence for the efficacy of Jungian psychotherapy has a specialized method.

With an average of only 90 sessions Jungian psychotherapy is a very time- and costeffective form of long-term psychodynamic psychotherapy. All of these results point clearly in the direction of effectiveness of Jungian psychotherapy. A severe problem that comes to light in the overview of the studies is the fact that Jungian analysts tend to be very reluctant in participating in empirical studies. As a consequence the German Association of AP and its training institutes have decided that future training candidates will have to apply a set of empirical measures (Symptom Rating, life satisfaction, OPD) to their training cases in order to form a database and to make ongoing quality management possible. In the long run this aims at creating a more open attitude to empirical research in the coming generations of Jungian analysts. On the other hand this process aims at stabilizing the currently comfortable position Jungian therapy has in the German healthcare system for the future by delivering empirical results about the effectiveness of the methods and applying standard quality management processes.

\section{CONFLICT OF INTEREST}

The author declares that there is no conflict of interest.

\section{REFERENCES}

Bischof, F., Riehl-Emde, A., \& Willi, J. (1994). Psychiater und ihre patienten: Ein vergleich zwischen der Poliklinik des Universitätsspitals Zürich und der freien praxis [Psychiatrists and their patients: A comparison between the Polyclinic of the University Hospital Zurich and the independent practice] [Unpublished doctoral dissertation]. University of Zürich, Switzerland.

Breyer, F., Heinzel, R., \& Klein, T. (1997). Kosten und nutzen ambulanter psychoanalyse in Deutschland [Costs and benefits of outpatient psychoanalysis in Germany]. Gesundheitsökonomie und Qualitätsmanagement, 2, 59-73.

Gerdes, N., \& Jäckel, W. H. (1992). Indikatoren des reha-status [Indicators of reha-status]. Rehabilitation, 31(2), 73-79.

Grawe, K., Donati, R., \& Bernauer, F. (1994). Psychotherapie im wandel [Psychotherapy in transition]. Hogrefe.

Hoffmeister, J., Hoeltz, J., Schön, D., Schröder, E., \& Güther, B. (1988). Nationaler untersuchungs-survey und regionale untersuchungs-surveys der DHP [National investigation survey and regional investigation surveys of the DHP]. DHP Forum, 3, 18-37.

Huber, D., Zimmermann, J., Henrich, G., \& Klug, G. (2012). Comparison of cognitive-behaviour therapy with psychoanalytic and psychodynamic therapy of depressed patients: A three-year follow up study. Zeitschrift für Psychosomatische Medizin und Psychotherapie, 58(3), 299-316. https://doi.org/ 10.13109/zptm.2012.58.3.299

Junghan, M. (2002). Die anwendung der strukturachse der OPD in der analytischen psychologie [The application of the structural axis of the OPD in analytical psychology]. In G. Rudolf, T. Grande, \& P. Henningsen (Eds.), Die struktur der persönlichkeit (pp. 90-114). Schattauer. 
Keller, W., Westhoff, G., Dilg, R., Rohner, R., Studt, H. H., \& The Study Group on Empirical Psychotherapy Research in Analytical Psychology. (2002). Efficacy and cost effectiveness aspects of outpatient (Jungian) psychoanalysis and psychotherapy: A catamnestic study. Itudy. In M. Leuzinger-Bohleber \& M. Target (Eds.), Outcomes of longer-term psychoanalytic treatment: Perspectives for therapists and researchers (pp. 110-120). Whurr.

Leichsenring, F., \& Klein, S. (2014). Evidence for psychodynamic psychotherapy in specific mental disorders: A systematic review. Psychoanalytic Psychotherapy, 28(1), 4-32. https://doi.org/10.1080/ 02668734.2013 .865428

Leichsenring, F., Luyten, P., Hilsenroth, M. J., Abbass, A., Barber, J. P., Keefe, J. R., Leweke, F., Rabung, S., \& Steinert, C. (2015). Psychodynamic therapy meets evidence-based medicine: A systematic review using updated criteria. Lancet Psychiatry, 2(7), 648-660. https://doi.org/10.1016/S2215-0366 (15)00155-8

Luborsky, L., Singer, B., \& Luborsky, L. (1975). Comparative studies of psychotherapy. Archives of General Psychiatry, 32(8), 995-1008. https://doi.org/10.1001/archpsyc.1975.01760260059004

Mattanza, G., Jakobsen, T., \& Hurt, J. (2006). Jung'sche psychotherapie ist effizient [Jung's psychotherapy is efficient]. In G. Mattanza, I. Meier, \& M. Schlegel (Eds.), Seele und forschung (pp. 38-82). Karger.

Nübling, R., Bär, T., Jeschke, K., Ochs, M., Sarubin, N., \& Schmidt, J. (2014). Versorgung psychisch kranker erwachsener in Deutschland [Care for mentally ill adults in Germany]. Psychotherapeutenjournal, 13(4), 389-397.

Roesler, C. (2012). Are archetypes transmitted more by culture than biology? Questions arising from conceptualizations of the archetype. Journal of Analytical Psychology, 57(2), 223-246. https:// doi.org/10.1111/j.1468-5922.2011.01963.x

Roesler, C. (Ed.). (2018). Research in analytical psychology: Empirical research. Routledge.

Rubin, S. I., \& Powers, N. (2005). Analyzing the San Francisco Psychotherapy Research Project. https://sirseth.net/doc/SFresearch.pdf

Rudolf, G., Grande, T., Jakobsen, T., Krawietz, B., Langer, M., \& Oberbracht, C. (2004). Effektivität und effizienz psychoanalytischer langzeittherapie: Die praxisstudie analytische langzeittherapie [Effectiveness and efficiency of long-term psychoanalytic therapy: The practical study of long-term analytical therapy]. In A. Gerlach, A. Schlösser, \& A. Springer (Eds.), Psychoanalyse des glaubens (pp. 515-528). Psychosozial.

Schach, E., Schwartz, F. W., \& Kerek-Bodden, H. E. (1989). Die EVaS-Studie: Eine erhebung über die ambulante medizinische versorgung in der BRD [The EVaS study: A survey on outpatient medical care in the BRD]. ZKV.

Schepank, H. (1994). Der Beeinträchtigungsschwere-Score (BSS) für psychogene erkrankungen [The Beeinträchtigungsschwere-Score (BSS) for psychogenic disorders]. Beltz.

Tschuschke, V., Crameri, A., Koehler, M., Berglar, J., Muth, K., Staczan, P., von Wyl, A., Schulthess, P., \& Koemeda-Lutz, M. (2015). The role of therapists' treatment adherence, professional experience, therapeutic alliance, and clients' severity of psychological problems: Prediction of treatment outcome in eight different psychotherapy approaches. Preliminary results of a naturalistic study. Psychotherapy Research, 25(4), 420-434. https://doi.org/10.1080/10503307.2014.896055

Wampold, B. E., \& Imel, Z. E. (2015). The great psychotherapy debate. Routledge.

Westen, D., \& Morrison, K. (2001). A multidimensional meta-analysis of treatments for depression, panic, and generalized anxiety disorder: An empirical examination of the status of empiricially supported therapies. Journal of Consulting and Clinical Psychology, 69(6), 875-899. https://doi.org/10.1037/ 0022-006X.69.6.875

Yakeley, J. (2018). Psychoanalysis in modern mental health practice. Lancet Psychiatry, 5(5), 443-450. https://doi.org/10.1016/S2215-0366(18)30052-X

(Manuscript received 17 August, 2018; Revision accepted 25 October, 2018; Released online in J-STAGE as advance publication 19 February, 2021) 